\title{
EL TRABAJO DE LOS EXTRANJEROS EN LA JURISPRUDENCIA
}

\section{THE WORK OF THE FOREIGNERS IN SPAIN: JURISPRUDENTIAL DEVELOPMENT}

\author{
Antonio V. Sempere Navarro \\ Universidad Rey Juan Carlos, Madrid. España/Spain \\ asempere@,fcjs.urjc.es
}

Recibido/Received: 11/08/2014

Modificado/Modified: 22/08/2014

Aceptado/Accepted: 23/09/2014

\section{RESUMEN}

Este es un artículo sobre el desarrollo jurisprudencial derivado de la situación del no nacional en el ámbito de las relaciones laborales y de Seguridad Social.

\section{PALABRAS CLAVE}

Jurisprudencia, doctrina, derecho extranjero, no nacional, relaciones laborales.

\section{SUMARIO}

1. Preámbulo. 2. Aplicación de normas. 3. Ausencia de permiso de trabajo. 4. Desempleo. 5. Responsabilidad empresarial por prestaciones de Seguridad Social. 6. Asistencia sanitaria en el extranjero. 7. Ámbito de la jurisdicción española.

\section{ABSTRACT}

This article is about the jurisprudential developments derivative of the situation of not native in the area of the labor relations and of National Health Service.

\section{KEYWORDS}

Jurisprudence, doctrine, foreign law, no national, labor relations.

\section{CONTENTS}

1. Preamble. 2. Application of rules. 3. Absence of work license. 4. Unemployment. 5. Managerial responsibility for presentations of National Health Service. 6. Sanitary assistance abroad. 7. Area of the Spanish jurisdiction.

\section{PREÁMBULO}

El tema elegido para las páginas que siguen quiere concordar con el enfoque que Barataria dispensa al presente número. Conviene introducirlo mediante unas breves y directas precisiones metodológicas: 
- La exposición está construida desde premisas jurídicas, dirigiéndose de modo muy especial a quienes cultivan tal tipo de ciencia, sin perjuicio de que intente ser comprensible para cualquiera.

- El estudio acoge un criterio estricto de "Jurisprudencia", de modo que únicamente examina doctrina sentada por el Tribunal Supremo, en concreto por su Sala Cuarta (cúspide de la organización jurisdiccional en el orden social).

- Para centrar el asunto exclusivamente en el alcance de la doctrina acuñada por esta vía, se ha optado por eliminar referencias bibliográficas o citas doctrinales, lógicamente, sin perjuicio de una mínima valoración a medida que se va exponiendo la materia.

- El alcance de lo que sea la extranjería se reconduce a la condición de no-nacional, con el recurso dialéctico de que los propios españoles adquieren esa condición en el momento en que traspasan las fronteras del Estado.

- De igual modo, la acepción del "trabajo" se reconduce al ámbito de las relaciones laborales y de Seguridad Social.

No se pretende obtener conclusión específica alguna, sino que se trata de revisar el tipo de asunto que ha accedido a la casación (unificación de doctrina, en concreto) y que posee parentesco directo con la toma en consideración de elementos no españoles. Pese a la fuerte internacionalización de nuestras relaciones de producción lo cierto es que escasean los supuestos del tipo examinado, probablemente porque el Derecho del Trabajo y de la Seguridad Social neutraliza la valencia de la extranjería cuando refiere a la nacionalidad del empleador o de la persona que trabaja, cuestiones inicialmente indiferentes. Otra cosa sucede cuando la actividad se lleva a cabo fuera de España o cuando se pretende invocar aquí la aplicación de preceptos extranjeros.

\section{APLICACIÓN DE NORMAS}

La extranjería o internacionalidad puede suscitar dudas acerca de si procede aplicar la legislación laboral española fuera de nuestras fronteras, pero también respecto del modo en que un ordenamiento foráneo gobierne el acontecer de una relación de trabajo que discurra en nuestro país. Ambas cuestiones tienen tratamiento en la jurisprudencia unificada.

A la hora de examinar la posible aplicación del ordenamiento español fuera del territorio estatal suele hacerse mención de una tripleta de normas: el art. 10.6 del Código Civil ("A las obligaciones derivadas del contrato de trabajo, en defecto de sometimiento expreso de las partes y sin perjuicio de lo dispuesto en el apartado 1 del artículo 8, les será de aplicación la ley del lugar donde se presten los servicios"), el art. 1.4 del Estatuto de los Trabajadores ("La legislación laboral española será de aplicación al trabajo que presten los trabajadores españoles contratados en España, al servicio de empresas españolas en el extranjero, sin perjuicio de las normas de orden público aplicables en el lugar de trabajo. Dichos trabajadores tendrán, al menos, los derechos económicos que les corresponderían de trabajar en territorio español") y el correspondiente precepto de Derecho Comunitario, asumiendo el viejo art. 6 del Convenio de Roma de 19 de junio de 1980 (la "ley aplicable" al contrato de trabajo debe ser la pactada o, en su defecto, la del lugar donde habitualmente se desarrolle la actividad laboral. Tal y como su propia denominación indica, se está ante norma aplicable a las obligaciones contractuales en la que se determina la legislación que ha de regular una relación jurídica en la que exista algún elemento de extranjería. Esa idea se confirma por el propio Convenio puesto que su art. 1.2.h) advierte que el mismo no se aplica "al proceso" y el art. 10, al especificar el ámbito de la ley del contrato, omite la determinación de la 
jurisdicción competente. Si acaso, podría dudarse qué significa el art. 10.2, conforme al cual "en lo que se refiere a las modalidades del cumplimiento y a las medidas que debe tomar el acreedor en caso de cumplimiento defectuoso, se tendrá en cuenta la Ley del país donde tenga lugar el cumplimiento", pero el contexto de la norma y las previsiones ya referidas conducen a descartar la virtualidad jurisdiccional de tal previsión). Respecto del fenómeno inverso, se admite la virtualidad de la ley extranjera siempre que tenga conexión con el negocio, según exige el art. 10.5 del CC, y sólo en defecto de tal sometimiento remite a la lex loci executioni.

Otras reglas del Convenio de Roma erigen la ley del lugar de prestación de los servicios en la norma por la que, generalmente, se va a disciplinar el contenido y el devenir de la relación. La solución favorable a la autonomía de la voluntad de las partes tiene dos importantes excepciones: $1^{\text {a }}$ ) Ninguna previsión material de Derecho extranjero puede ser aplicada en España si resulta incompatible con las normas internas de orden público (art. 16, a sensu contrario); $2^{a}$ ) La elección de la prescripción extranjera "no podrá tener por resultado el privar al trabajador de la protección que le proporcionen las disposiciones normativas de la ley que sería aplicable a falta de elección..." (art. 6.1), ley aplicable en defecto de elección que, normalmente, y según el propio Convenio de Roma, será la ley del lugar de ejecución habitual del trabajo o lex loci laboris, que pasa de este modo a erigirse en norma de mínimos.

\subsection{Derecho español en el extranjero}

\subsubsection{Españoles en el Servicio Exterior}

Se discute si la legislación española es aplicable para resolver una pretensión laboral (demanda por despido) planteada por español que presta sus servicios en determinado Consulado, teniendo en cuenta que el contrato de trabajo (tras la selección llevada a cabo en la ciudad donde radica el Consulado) se perfecciona en Madrid.

No se cuestiona la competencia de los órganos jurisdiccionales españoles sino el Derecho sustantivo que hayan de aplicar. Frente a la prevalencia de las normas propias del país de trabajo que se detecta tanto el Convenio de Roma cuanto el Código Civil, la específica regla del artículo 1.4 ET apunta hacia las normas españolas.

El Tribunal Supremo entiende que la legislación española rige los contratos de trabajo de los españoles al servicio de legaciones diplomáticas en el extranjero si el contrato de trabajo también se ha perfeccionado en España: "siendo la empresa y el trabajador españoles y habiéndose celebrado el contrato en Madrid, y nombrado el actor para el cargo también en Madrid, por el Ministerio de Asuntos Exteriores, es claro que la ley aplicable a la cuestión litigiosa es la española" (STS 18 mayo 1999 (RJ 1999, 4833) (Ponente, Sr. Sampedro Corral)). De este modo, la jurisprudencia se inclina por otorgar primacía a la legislación laboral española, descartando la regla territorialista que suele imperar a la hora de determinar la norma aplicable.

En concordancia con ello se explica que la laboralización de los contratos administrativos del personal al servicio de Embajadas españolas, aunque formalmente aprobada en nuestro país, no significa que estemos ante contratos celebrados en España (SSTS 5 diciembre 2002 (RJ 2003, 518) (Ponente, Sr. Bris Montes) y 17 febrero 2003 (RJ 2003, 3242)). 


\subsubsection{Exclusión del convenio colectivo español}

Se ha discutido si puede reputarse legítima la exclusión que el convenio colectivo de un concreto Departamento ministerial contempla respecto de su personal laboral que le presta servicios en el extranjero.

La solución pasa por recordar que los convenios tendrán el ámbito de aplicación que las partes acuerden; pero esta amplia libertad de determinación de la concreta unidad negocial no significa que, de modo arbitrario e irrazonable, puedan las partes excluir de la eficacia del convenio a un determinado grupo de trabajadores, pues su facultad se encuentra sujeta a ciertos límites, cuales son el respeto a la ley y a los mínimos de Derecho necesario (arts. 85. 1 y 3.3 ET), evitando lesionar los derechos de terceros (art. 90.5 ET).

Sobre tales presupuestos, el problema queda referido a la objetividad y razonabilidad de la exclusión enunciada. Para el Tribunal Supremo, la respuesta afirmativa debe imponerse, pues la exclusión no afecta a trabajadores que tienen unos haberes ordinarios y tareas comunes, en los que el único factor diferencial es la temporalidad del vínculo, sino a colectivos profesionales que tienen unas características específicas y condiciones concretas derivadas del centro, sito en país extranjero, donde prestan sus funciones. El Derecho no impide que un convenio colectivo (para personal de Administraciones Públicas) margine de su ámbito aplicativo a quienes prestan sus servicios en el extranjero (SSTS 17 junio 1994 (RJ 1994, 5448) (Ponente, Sr. Sampedro Corral); 17 marzo 1995 (RJ 1995, 2023)).

\subsubsection{Identificación de trabajadores en el exterior excluidos}

Una segunda cuestión, muy relacionada con la anterior y de suma relevancia práctica, se plantea respecto de la identificación del colectivo excluido del convenio colectivo en cuestión (convenio único del Personal al servicio de la Administración del Estado).

Puesto que los documentos contractuales suelen tramitarse y aprobarse por un órgano ministerial radicado en Madrid (Subdirección General de Personal) y puesto que (como se ha visto) la legislación española rige las relaciones laborales de los españoles al servicio de legaciones diplomáticas en el extranjero cuando el contrato de trabajo también se ha celebrado en España, el lugar de perfeccionamiento del contrato (por parte empresarial) determina un punto de conexión favorable a la aplicación de la norma convencional.

Sin embargo, el Tribunal Supremo descarta ese modo de enfocar las cosas; no se trata de determinar si la legislación española resulta de aplicación, sino de clarificar el alcance excluyente de la previsión convencional. Desde tal perspectiva, la hermenéutica razonable sobre el alcance de la expresión "personal laboral contratado en el exterior" la hace equivaler a personal contratado "para trabajar en el exterior", neutralizando las consecuencias del dato referido al lugar de perfeccionamiento o firma del contrato; lo relevante es la prestación de la actividad fuera de España, con independencia del lugar de celebración del contrato de trabajo (SSTS 13 (2) mayo 2003 (RJ 2003, 9159 y 9160; Sala general) (Ponente, Sr. García Sánchez); 30 enero 2004 (RJ 2004, 1692); 3 febrero 2004 (RJ 2004, 1290); 26 octubre 2004 (RJ 2004, 6650)), como se comprueba desde varios puntos de vista:

- Argumento teleológico: la sinrazón de que el régimen convencional resultara aplicable o no en función de "un dato sumamente azaroso" como el lugar en que se firma el contrato.

- Argumento histórico: precedentemente, en los Convenios Colectivos para el personal laboral del Ministerio (de Economía y Hacienda) quedaba excluido "el personal laboral destinado en el extranjero".

- Actos coetáneos y posteriores: la Administración y los sindicatos han concluido otros acuerdos específicos sobre condiciones laborales del personal del servicio exterior. 


\subsubsection{Contratos previos al Convenio de Roma}

Se ha discutido la legislación aplicable a unos contratos de trabajo celebrados en España por trabajadores españoles con empresa de la misma nacionalidad, para prestar servicios en la Sucursal del Banco empleador en Frankfurt. Todo ello a propósito de extinción contractual acordada por la empresa e impugnada ante los Tribunales Españoles. Consta acreditado el Derecho alemán, en lo referente al despido y otras extinciones contractuales, en debida forma (La sentencia recurrida declaró que el Derecho aplicable era el alemán y, en consecuencia, decretaba procedentes las extinciones contractuales "en función de la normativa alemana reguladora del contrato laboral de cada actor". En cambio, la sentencia de contraste, enjuiciando el despido de un trabajador español contratado en España al servicio del Ministerio de Asuntos Exteriores, para prestar su servicio en Tánger, llega a la conclusión de que el Derecho español es el aplicable).

Para el Alto Tribunal, los contratos de trabajo celebrados en España, antes de la entrada en vigor del Convenio de Roma, por trabajadores españoles con empresa de la misma nacionalidad para prestar servicios en el extranjero, se rigen por la legislación laboral española en defecto de opción expresa por norma extranjera distinta (STS de 17 enero 2005 (RJ 2005, 776) (Ponente, Sr. Martínez Garrido)). Nótese que el Convenio de Roma de 1980, al que España se adhirió el 18 de mayo de 1992, se aplica desde el 1 de septiembre de 1993.

A partir de la entrada en vigor del Convenio de Roma, "su texto debe prevalecer sobre el de la norma nacional", que así habría perdido su carácter de ius cogens, y acto seguido añade que "son principios básicos el que las partes pueden elegir la norma aplicable a todo o a parte del contrato (artículo 3) y, en defecto de elección, en el supuesto del contrato de trabajo, la norma a aplicar es la vigente en el lugar de prestación de los servicios".

\subsection{Derecho extranjero en España}

\subsubsection{Planteamiento}

La aplicación del Derecho extranjero es una materia de Derecho Internacional Privado. Las reglas de los arts. 8 a 12 del Código Civil deben ser convenientemente reinterpretadas a la luz de los compromisos adquiridos por España tras su adhesión a diversos tratados y convenios internacionales en la materia, entre los que sobresale el Convenio de Roma de 1980 sobre la ley aplicable a las obligaciones contractuales (ratificado por Instrumento de 7 mayo 1993).

\subsubsection{Criterio inicial}

El supuesto base surge porque una mujer, de nacionalidad guatemalteca, con domicilio en la ciudad estadounidense de Los Ángeles, sin que conste en parte alguna que haya residido ni estado en España, suscribió contrato de trabajo con el Consulado General de España, en virtud del cual llevó a cabo la labor de empleada de limpieza; se discute el ordenamiento regulador de la extinción de su contrato de trabajo.

Tras un fuerte debate interno, la Sala Cuarta entendió que si el Derecho aplicable según la regla de conflicto es el extranjero, la parte que formule la pretensión tiene que alegar y probar ese Derecho; si no lo hace, o lo invoca pero no lo acredita, la pretensión debe ser desestimada (STS 22 mayo 2001 (RJ 2001, rec. 2507/2000) (Ponente, Sr. Gil Suárez), dictada en Pleno con Voto Particular de diversos Magistrados). Eso supone el desmarque respecto de la tesis tradicional según la cual rige el Derecho interno cuando no se acrediten suficientemente el contenido y vigencia del extranjero: la falta de alegación y prueba no puede conducir a la 
aplicación de la ley española, pues ello equivaldría al absurdo de sancionar la omisión de prueba (puede que deliberada) de la norma extranjera con la aplicación de la ley española, cuando se considerase que ésta era más beneficiosa.

Se descarta que la parte sólo esté obligada a probar el Derecho extranjero si lo invoca expresamente como fundamento de su pretensión, con independencia de que la legislación foránea resulte aplicable conforme a las normas de conflicto. No es admisible que la aplicación del Derecho extranjero quede al albur de la actividad probatoria de quien, en algún caso, puede no estar interesado en su aplicación.

\subsubsection{Criterio revisado y actual}

Las SSTC 10/2000, de 17 de enero; 155/2001, de 2 de julio y 33/2002, de 11 de febrero consideran que es más respetuoso con el derecho a la tutela judicial efectiva aplicar el Derecho español ante la falta de prueba del Derecho Extranjero. Se estima constitucionalmente inaceptable que el Tribunal del Orden Jurisdiccional Social omita pronunciamiento de fondo por falta de acreditación de la legislación extranjera cuando la norma de conflicto la señala como aplicable, pues en tal caso ha de aplicarse subsidiariamente la lex fori, la legislación laboral española. Incluso se añade que no debía hacerse recaer sobre la demandante los efectos desestimatorios de su pretensión por falta de acreditación de la existencia y alcance de una norma extranjera, cuya aplicación ni siquiera invocó, sino que tales efectos adversos deberán recaer sobre la parte que invocó tal aplicabilidad, la empresa demandada.

A la vista de ello, no sin nueva polémica, el Tribunal Supremo acabó entendiendo que en estos casos ha de resolverse el pleito conforme al Derecho español, por así exigirlo la tutela judicial efectiva (STS 4 noviembre 2004 (RJ 2005, 1056; Pleno) (Ponente, Sr. Gullón Rodríguez; Voto Particular del Sr. Sampedro; Voto Particular del Sr. Gil Suárez con adhesión de los Sres. Iglesias y Sampedro)).

\section{AUSENCIA DE PERMISO DE TRABAJO}

\subsection{El problema y su solución tradicional.}

Dispone el art. 7.c) ET que los extranjeros pueden concertar la prestación de su trabajo "de acuerdo con lo dispuesto en la legislación específica sobre la materia". A su vez, estas normas les exigen la obtención de permiso de residencia y de trabajo.

La inmensa mayoría de la doctrina y los tribunales preconizaban que cuando se desarrolla una actividad productiva careciendo de esa autorización, dada la insubsanable falta de capacidad subjetiva, lo que existía era un contrato nulo (sin perjuicio del derecho a percibir los salarios correspondientes al trabajo realizado, ex art. 9.2 ET), por lo que, entre otras consecuencias, sería impensable hablar de despido. Este criterio acabó siendo asumido por la jurisprudencia unificada en la conocida STS de 21 de marzo de 1997 (RJ 1997, 3391), la cual explicaba que en el caso de prescindir el empleador de los servicios del trabajador extranjero éste carecía de acción para impugnar el despido (técnicamente inexistente); los artículos 6.3 ("Los actos contrarios a las normas imperativas y a las prohibitivas son nulos de pleno derecho, salvo que en ellas se establezca un efecto distinto para el caso de contravención") y 1275 ("Los contratos sin causa, o con causa ilícita, no producen efecto alguno. Es ilícita la causa cuando se opone a las leyes o a la moral") del CC se invocaban también en ese contexto argumental. Esta tesis entroncaba con un criterio jurisprudencial ya reiterado conforme al cual, partiendo de que es obligatorio para el trabajador extranjero no comunitario 
hallarse en posesión de los permisos de trabajo y residencia, la carencia de éstos -bien originaria, bien por falta de renovación-, convierte en nulo el contrato de trabajo así estipulado, al ser contrario a una norma prohibitiva (STS 27 noviembre 1989 (RJ 1989, 8257)).

\subsection{Criterio al amparo de la LO de 2000}

Conforme al artículo 33.3 de la LO 4/2000 "los empleadores que contraten a un trabajador extranjero deberán solicitar y obtener autorización previa del Ministerio de Trabajo y Asuntos Sociales. La carencia de la correspondiente autorización para contratos por parte del empleador, sin perjuicio de las responsabilidades a que dé lugar, no invalidará el contrato de trabajo respecto a los derechos del trabajador extranjero" (el precepto nos situaba ante una de las instituciones más enigmáticas y confusas de la Ley: la autorización administrativa para que los empleadores contraten trabajadores extranjeros; de este modo, se abría paso un perturbador y dual camino de autorizaciones: la del trabajador y la de su empleador, aunque lo cierto es que esta segunda jamás llegó a desarrollarse reglamentariamente ni a ponerse en práctica).

Mediante LO 8/2000 se modificó prontamente la previsión; al art. 36.3 hablaba de "Los empleadores que deseen contratar a un extranjero no autorizado para trabajar deberán obtener previamente, conforme a lo dispuesto en el apartado 1 de este artículo, autorización del Ministerio de Trabajo y Asuntos Sociales", por lo que se acababa exigiendo el clásico permiso de trabajo y no otro diverso. Lo que sucede es que el segundo período del precepto no se ha modificado y sigue aludiendo a un supuesto ("carencia de la correspondiente autorización por parte del empleador") que ha desaparecido, al abandonarse la idea de que la empresa precise un permiso diverso al de su asalariado. Pese a estar ante un tema de la máxima trascendencia (el contrato no se invalida, aunque tampoco exista la autorización) y a reclamarse doctrinalmente que la tramitación parlamentaria clarificase tal galimatías, no se hizo así.

Enjuiciando accidente acaecido cuando estaba vigente la versión primera de la LOEx el Supremo proclamó que el contrato de trabajo del trabajador extranjero sin autorización para trabajar no es, en la actual legislación, un contrato nulo (SSTS 9 junio 2003 (RJ 2003, 3936) (Ponente, Sr. Martínez Garrido); 29 septiembre 2003 (RJ 2003, 7446)). El discurso de la Sala Cuarta se antoja excesivamente escueto por un doble motivo: porque prescinde de rebatir las serias argumentaciones opuestas a la tesis acogida y porque deja en el tintero otros tantos pilares en los que puede basarse su posición (que concuerda con el tenor literal de diversas normas internacionales y comunitarias, en las que se atribuyen derechos a "los trabajadores", sin especificación alguna de más requisitos).

\subsection{Criterio al amparo de la LO de 2003}

La LO 4/2003, de 20 de noviembre, vino a enriquecer la redacción del artículo 33.3 LOEx, dejando meridianamente claro que el contrato de trabajo celebrado con un extranjero no comunitario sin autorización desplegaba todos sus efectos respecto a los derechos del trabajador extranjero. Dicha redacción, aún vigente, además de establecer que ha de ser el empleador el que "deberá solicitar la autorización a que se refiere" la norma, prevé de modo literal que la carencia de ella "por parte del empresario, sin perjuicio de las responsabilidades a que dé lugar, incluidas aquellas en materia de seguridad social, no invalidará el contrato de trabajo respecto a los derechos del trabajador extranjero, ni será obstáculo para la obtención de las prestaciones que pudieran corresponderle". 
A la vista de ello la Sala Cuarta explica que si bien el contrato de trabajo del extranjero concertado sin la preceptiva autorización está afectado de la sanción de nulidad que establece la ley, sin embargo, la misma ley salva la sanción de nulidad proclamando su validez respecto a los derechos del trabajador afectado. De este modo, ejemplificando, procede el abono de la indemnización y los salarios de tramitación al trabajador extranjero no autorizado a trabajar que es despedido improcedentemente, por la validez y consecuente eficacia de su contrato respecto a los derechos que consagra la ley para cualquier trabajador (SSTS de 21 junio 2011 (RJ 2011, 5942) (Ponente, Sr. Gilolmo López) y 17 septiembre 2013 (RJ 2013, 7309)).

\section{DESEMPLEO}

\subsection{Exportación de prestaciones}

El art. 213.1 LGSS establece que el derecho a la percepción de la prestación por desempleo se extinguirá en caso de traslado de residencia al extranjero, salvo en los casos que reglamentariamente se determinen, lo que remite al art. 6.3 del RD 625/1985, de 2 de abril, en redacción dada por RD 200/2006, de 17 de febrero ("El derecho a la prestación o al subsidio por desempleo quedará suspendido en los supuestos de traslado de residencia al extranjero en los que el beneficiario declare que es para la búsqueda o realización de trabajo, perfeccionamiento profesional, o cooperación internacional, por un periodo continuo inferior a doce meses, sin perjuicio de la aplicación de lo previsto sobre la exportación de las prestaciones en los convenios o normas comunitarias. En otro caso el traslado de residencia al extranjero incumpliendo alguno de los requisitos anteriores supondrá la extinción del derecho).

El artículo 64 del Reglamento comunitario 883/2004, sobre coordinación de los sistemas de Seguridad Social, proporciona determinadas reglas (para desplazamientos en el ámbito de la Unión Europea) o pautas normativas (para otros desplazamientos) con arreglo a las cuales se ha de medir (o se puede medir), en los casos de salida al extranjero, el cumplimiento de los deberes del beneficiario de "permanecer a disposición de los servicios de empleo del Estado miembro competente" que abona la prestación. Entre estos criterios figura el sometimiento del beneficiario "al procedimiento de control organizado en éste" [el Estado que paga la prestación] [art. 64..1. b)], el cumplimiento "de los requisitos que establezca la legislación de dicho Estado miembro" [art. 64..1. b)], y la conservación en principio del "derecho a las prestaciones durante un período de tres meses a partir de la fecha en que haya dejado de estar a disposición de los servicios de empleo del Estado miembro del que proceda" [art. 64..1. c)].

\subsubsection{Doctrina inicial}

En un primer momento, el Supremo entendió que pierde el derecho a la prestación por desempleo el beneficiario que viaja al extranjero, por motivos familiares, por tiempo superior a quince días, sin comunicarlos al SPEE (SSTS de 22 noviembre 2011 (RJ 2012, 765) (Ponente, Sra. Segoviano Astaburuaga) y 17 enero 2012 (RJ 2012, 3511)).

\subsubsection{Criterio superador}

Rectificando el expuesto criterio, ahora se sostiene que el desplazamiento al extranjero por un tiempo inferior a 90 días no supone un traslado de residencia y tampoco determina la extinción de la prestación por desempleo, sino su suspensión, comportando, en su caso, la pérdida de la cantidad correspondiente a los días de estancia no autorizada en el extranjero 
(SSTS de 18 octubre 2012 (RJ 2012, 10707) (Ponente, Sr. Martín Valverde, con Voto Particular de la Magistrada Calvo Ibarlucea); 23 octubre 2012 (RJ 2013, 1561); 4 y 13 noviembre 2013 (RJ 2014, 379 y RJ 2013, 8489)). La muy elaborada construcción jurisprudencial permite diferenciar lo siguiente:

- una prestación "mantenida" en los supuestos de salida al extranjero por tiempo no superior a quince días naturales al año, por una sola vez, siempre que el desplazamiento se haya comunicado a la Administración española en tiempo oportuno;

- una prestación "extinguida", con la salvedad que se indica a continuación, en los supuestos de prolongación del desplazamiento al extranjero que comporte "traslado de residencia", es decir, por más de los noventa días que determinan en la legislación de extranjería el paso de la estancia a la residencia temporal;

- una prestación "suspendida" en el supuesto particular del art. 6.3 del RD 625/1985 (redacción por RD 200/2006 (RCL 2006, 467)) de "búsqueda o realización de trabajo" o "perfeccionamiento profesional" en el extranjero por tiempo inferior a "doce meses";

- una prestación "suspendida", en todos los demás supuestos en que se haya producido el desplazamiento al extranjero por tiempo inferior a noventa días, con la consiguiente ausencia del mercado de trabajo español del beneficiario de la prestación de desempleo. La razón de la extinción es que el preceptor de prestación de desempleo tiene que cumplir las obligaciones impuestas en el artículo 231 de la Ley General de la Seguridad Social, muchas de las cuales resultan imposibles de cumplir si el trabajador no permanece en España.

La Sala advierte que la precisión del concepto legal, a efectos del "traslado de residencia" que extingue, en principio, la prestación de desempleo, rectifica la posición doctrinal adoptada en precedentes sentencias, de acuerdo con las cuales si la norma reglamentaria dice que no es traslado de residencia la salida por tiempo inferior a quince días, se puede entender que sí lo es, según la propia norma reglamentaria, el desplazamiento superior a ese período. Esta posición se apoya en un argumento de lógica abstracta (argumento inclusio unius, exclusio alterius o argumento sensu contrario) "que vale desde luego para las enumeraciones o listas legales exhaustivas, pero que, por lo ya dicho, no resulta convincente para la solución de la presente cuestión interpretativa".

El art. 231.1 LGSS se refiere a la obligación de comunicación previa o inmediata, indicando que las solicitudes o informaciones relevantes sobre protección del desempleo han de tener lugar "en el momento de la producción de dichas situaciones", momento que se actualiza cuando existe un concreto programa de viaje que coloca al beneficiario fuera de la órbita de actuación de los servicios públicos de empleo y de la Administración de la Seguridad Social española. Sin comunicación por anticipado (o comunicación inmediata en caso de que la información previa hubiera sido imposible o excesivamente onerosa) no hay modo de controlar el cumplimiento de los requisitos del derecho a la prestación; entre ellos, la voluntad de aceptar una oferta adecuada de trabajo o de formación en el territorio español, que en principio es el que delimita y al que se extiende la actuación de los servicios de empleo.

De acuerdo con el mismo precepto legal, las circunstancias sobrevenidas de cualquier clase (personales, familiares, de incidencias en los medios de transporte, etcétera) que puedan determinar o justificar una prolongación de la estancia en el extranjero más allá de lo inicialmente previsto deben también ser comunicadas de manera inmediata a la entidad gestora. Este deber de comunicación inmediata (y posterior documentación) de estancias más prolongadas en el extranjero por circunstancias sobrevenidas tiene su razón de ser en que las 
mismas afectan, al igual que ocurre con la salida o desplazamiento al extranjero, a la disponibilidad para actividades formativas o de trabajo en España.

Los medios de información a utilizar por los beneficiarios de las prestaciones de desempleo para el cumplimiento de los deberes señalados serán los habituales en las relaciones de los administrados con el Servicio Público de Empleo Estatal y con las entidades gestoras de Seguridad Social. Entre ellos se incluyen los medios informáticos o electrónicos previstos en la legislación española.

El incumplimiento de las obligaciones de comunicar ex ante (para la salida programada) o inmediatamente ex post (para una eventual circunstancia sobrevenida) genera de modo automático la suspensión o pérdida temporal ("baja") de la prestación de desempleo que corresponde a los días de estancia en el extranjero no comunicada: todos los días de estancia no comunicada si el incumplimiento ha sido total; o el exceso de días de estancia no comunicada, o no debidamente justificada, si el incumplimiento se refiere a una vuelta tardía.

Esta causa de suspensión de la prestación de desempleo no se menciona expresamente en el artículo 212 LGSS, pero responde a la razón de ser común que inspira a la mayor parte de dichas causas de suspensión de la protección. Se trata casi siempre de situaciones temporales en las que el beneficiario no está a disposición de los servicios de empleo españoles para actividades formativas o de trabajo, pero que no alcanzan la entidad o la gravedad de las causas de extinción de la prestación establecidas en el artículo 213 LGSS.

\subsection{Extranjeros con permiso temporal de residencia.}

Como elemento esencial de la contingencia de desempleo protegida por nuestro ordenamiento jurídico se encuentra la circunstancia de que sobrevenga la misma "pudiendo y queriendo trabajar" (art. 203.1 LGSS). Se plantea la duda de si esa posibilidad de trabajar, requisito imprescindible para que exista la protección, concurre en el caso de extranjero cuyo permiso de trabajo vence, aunque no así el de residencia.

La coetánea LOEx sometía la actividad por cuenta ajena al requisito de previa autorización; la concesión del permiso de trabajo se supedita "a que el solicitante presente contrato de trabajo por escrito o justifique documentalmente el compromiso formal de colocación por parte de la empresa que pretenda emplearlo" (art. 17.1). Expirada la vigencia de ese permiso, es posible solicitar permiso de residencia (art. 19.2) y, a su amparo, encontrar otro empleo e interesar la concesión de nuevo permiso de trabajo.

A la vista de esa construcción legal, el Supremo considera erróneo que cuando se haya cumplido el término del permiso de trabajo, pero se posea el de residencia, haya desaparecido la posibilidad de trabajar y, en consecuencia, las prestaciones por desempleo se extingan. Mientras el trabajador esté autorizado a residir legalmente en España cabe la posibilidad (por más que limitada en función de las circunstancias que se ponderan para decidir al respecto) de que acceda a un nuevo empleo; incluso la denegación del permiso de trabajo es compatible con la posibilidad de acceder a un nuevo empleo: la clave, por lo tanto, se encuentra en el título a cuyo amparo permanece el sujeto extranjero en España (permiso de residencia).

En suma, la prestación contributiva puede ser percibida por trabajador extranjero mientras se prolongue su residencia legal en territorio español (SSTS 21 diciembre 1994 (RJ 1994, 10349) (Ponente, Sr. Desdentado Bonete); 21 septiembre 1995 (RJ 1995, rec. 834/95); 25 septiembre 1995 (RJ 1995, rec. 3854)). La doctrina del Supremo suele ser favorablemente evaluada, situándose en la perspectiva constitucionalmente adecuada para hacer concordar los derechos (aunque limitados) de los extranjeros respecto de su residencia y trabajo en España (arts. 13 y $19 \mathrm{CE}$ ) con su protección frente al desempleo (art. $41 \mathrm{CE}$ ). Asimismo 
realiza una hermenéutica acertada del papel asumido por la autorización administrativa, diferenciando entre la imposibilidad material de trabajar en tanto no se haya producido, y la posibilidad teórica de que respecto de un empleo asimismo hipotético se concediera.

\subsection{Extranjeros en situación irregular}

Problema.- Se plantea ahora, de forma frontal, una cuestión muy relevante en la práctica: determinar si tiene derecho a inscribirse como demandante de empleo y percibir las prestaciones de desempleo un extranjero (cubano) que, sin autorización para residir ni para trabajar, ha trabajado (consecuentemente, sin alta en Seguridad Social) y cuyo despido fue declarado improcedente por sentencia firme.

La Sala sostiene que la prestación de desempleo sólo la puede obtener el extranjero residente que ha realizado servicios por cuenta ajena sin contar con la pertinente autorización para trabajar, pero no el que, como el actor, se encuentra en España en situación irregular.

Jurisprudencia previa.- Se descarta la aplicación del criterio unificado conforme al cual la prestación contributiva puede ser percibida por trabajador extranjero mientras se prolongue su residencia legal en territorio español (SSTS 21 diciembre 1994 (RJ 1994, 10349) (Ponente, Sr. Desdentado Bonete); 21 septiembre 1995 (RJ 1995, rec. 834/95); 25 septiembre 1995 (RJ 1995, rec. 3854)). Allí (sobre la base de la LOEx) se explicaba que cuando se haya cumplido el término del permiso de trabajo, pero se posea el de residencia, haya desaparecido la posibilidad de trabajar y, en consecuencia, las prestaciones por desempleo se extingan. Mientras el trabajador esté autorizado a residir legalmente en España cabe la posibilidad (por más que limitada en función de las circunstancias que se ponderan para decidir al respecto) de que acceda a un nuevo empleo; incluso la denegación del permiso de trabajo es compatible con la posibilidad de acceder a un nuevo empleo: la clave, por lo tanto, se encuentra en el título (permiso de residencia) a cuyo amparo permanece el sujeto extranjero en España. Por el contrario, en el caso presente se está ante persona que no ha llegado a contar con autorización para residir o trabajar en momento alguno.

Tampoco se contempla un asunto igual en sentencias invocadas como precedentes más o menos directos: la de 9 junio 2003 (RJ 2003, 3936) -se pronuncia sobre prestaciones de asistencia sanitaria e incapacidad temporal derivada de accidente de trabajo, y no sobre un desempleo; y lo hace, además, respecto de un nacional de Ecuador, país que si bien no ha ratificado el Convenio 19 OIT, si mantiene con España Convenio de Seguridad Social que impone el principio de igualdad de trato entre ambos países-, de 7 de octubre de 2003 (RJ 2003, 6497) -sobre IPA derivada igualmente de accidente de trabajo, y no un desempleo, respecto de un nacional de Colombia, país que si había ratificado en 1933 el Convenio 19 OIT- o de 29 septiembre 2003 (RJ 2003, 7446) -declara nulo el despido de un argentino sin permiso de residencia ni de trabajo aplicando el art. 36.2 en versión LO 4/2000, pero no hace pronunciamiento alguno respecto de prestaciones de Seguridad Social-.

Previsiones de la OIT.- El Convenio núm. 19 OIT, sobre la igualdad de trato en materia de indemnizaciones por accidentes del trabajo", ratificado por Cuba y España, no contiene previsión alguna sobre desempleo. El Convenio núm. 97 OIT, "relativo a los trabajadores migrantes", ratificado por España, reserva el principio de igualdad de trato en materia de Seguridad social solo a "los emigrantes que se encuentren legalmente" en el país (art. 6.1). La Recomendación 151 OIT, como todas ellas, contiene simples propuestas sin fuerza de obligar, además de que su art. 8.3 sostiene que los extranjeros "deberían disfrutar de la igualdad de trato". 
Previsiones de la LOEx.- El artículo 36 LOEx, tras su reforma de 2003 -regula la autorización para la realización de actividades lucrativas y en su apartado 3 prescribe que "Para la contratación de un extranjero el empleador deberá solicitar la autorización a que se refiere el apartado 1 del presente artículo. La carencia de la correspondiente autorización por parte del empresario, sin perjuicio de las responsabilidades a que dé lugar, incluidas aquellas en materia de seguridad social, no invalidará el contrato de trabajo respecto a los derechos del trabajador extranjero, ni será obstáculo para la obtención de las prestaciones que pudieran corresponderle"-, se inserta en la tendencia a ampliar la protección de los derechos laborales de los extranjeros, de los que se veían privados hasta entonces si no contaban con el correspondiente permiso de trabajo, de acuerdo con la jurisprudencia mayoritaria. Pero la sentencia va a explicar, de forma detallada, que de ahí no deriva el derecho al cobro de prestaciones por desempleo por parte de extranjero que ha trabajado en condiciones de irregularidad.

La Ley distingue claramente a lo largo de todo su articulado entre el extranjero residente y aquel que se encuentra en situación irregular y regula los derechos de unos y otros de manera distinta; en particular, el artículo 14 ("derecho a Seguridad Social y a los servicios sociales") explica que "los extranjeros residentes tendrán derecho a acceder a las prestaciones y servicios de la Seguridad Social en las mismas condiciones que los españoles" (apartado 1), mientras que "los extranjeros, cualquiera que sea su situación administrativa, tienen derecho a los servicios y prestaciones sociales básicas" (apartado 3); de ahí se deduce que los extranjeros en situación irregular "carecen del derecho a las prestaciones de la Seguridad Social que el párrafo primero solo reconoce a los extranjeros residentes", conclusión reforzada porque trabajar sin la oportuna autorización administrativa previa constituye para el extranjero en situación irregular, una falta grave (art. 53.b) LOEx).

El artículo 36.3 LOEx.- ¿Qué significa, entonces, el art. 36.3 LOEx cuando prescribe que la falta de la autorización para trabajar no será obstáculo para la obtención de las prestaciones que pudieran corresponder al extranjero? A la vista del razonamiento anterior, la respuesta es doble:

- Si cuenta con autorización de residencia tiene derecho a obtener las prestaciones de Seguridad Social, a las que tiene derecho en pie de igualdad con los trabajadores españoles.

- Si no cuenta con la autorización de residencia, no puede obtener las prestaciones propias de los residentes, sino los "servicios y prestaciones sociales básicas" (asistencia sanitaria de urgencia y asistencia social).

Esa conclusión se refuerza porque no es lógico que el extranjero en situación irregular pueda acceder por el hecho de cometer una falta grave que autoriza a su expulsión, a cualesquiera prestaciones de S. Social, a las que inicialmente y de acuerdo con el art. 14 de la misma LOEx, nunca tendría derecho. Tampoco sería lógico reconocer a los extranjeros en situación irregular los mismos derechos que a los residentes cuando es notorio que la legislación española de extranjería ha estado orientada siempre a estimular la emigración legal -la LO 4/2000 subraya que su objetivo es "incentivar a los extranjeros a entrar y residir en nuestro país dentro del marco de la regularidad, frente a la entrada y estancia irregular". Y la LO 14/2003 repite que la mejora de la gestión que establece tiene "el fin de favorecer la inmigración legal y la integración de los extranjeros que, de esta manera, accedan y residan en nuestro territorio"-; cosa distinta es que se exija al empresario infractor una responsabilidad indemnizatoria por daños y perjuicios, al margen del asunto aquí examinado -pero la ausencia de los requisitos para percibir las prestaciones por desempleo no puede ser imputable al empresario, salvo que éste forme parte de las "redes organizadas para la inmigración ilegal o el tráfico ilícito de mano de obra" de las que habla el art. 59 LOEx, 
puesto que la situación de irregularidad por ausencia de autorización de residencia, es previa a la contratación y solo responsabilidad del propio extranjero "no residente", que decidió entrar y permanecer ilegalmente en España; lo que impediría, incluso, el nacimiento de la responsabilidad indemnizatoria a la que hemos aludido en el fundamento quinto "in fine" y que en este caso no se ha solicitado-.

Diferencia entre accidente laboral y desempleo.- La examinada regulación de la LOEx ha llevado a que el propio Tribunal Supremo reconozca a los extranjeros no residentes el derecho a las prestaciones derivadas de contingencias profesionales, siempre que pertenezcan a país que haya suscrito el Convenio 19 OIT o que tenga suscrito Convenios con régimen de reciprocidad en la materia -en este sentido, por ejemplo, STS 19 junio 2003 (RJ 2003, 3936); el RD 1041/2005 asumió esa solución de forma expresa-. Sin embargo, no es posible extender esa solución al caso del desempleo:

- No existen Convenios Internacionales integrados en nuestra normativa interna, que así lo autoricen.

- Sería solución contraria a la finalidad de incentivar la entrada y la estancia regular de los extranjeros en España.

- Implicaría la creación judicial de una especie de regularización, encubierta y en espiral, del emigrante irregular (al no poder ser expulsado mientras estuviera percibiendo la prestación de desempleo).

Legislación de desempleo.- El art. 203.1 LGSS sólo otorga el derecho al desempleo a quienes "pudiendo y queriendo trabajar" pierden el empleo; y los extranjeros no residentes aunque quieran, no pueden trabajar legalmente puesto que no pueden obtener la pertinente autorización administrativa para ello, ya que ésta sólo se concede o a extranjeros ya residentes en España, bien a quienes llegan a ella provistos del permiso de residencia y trabajo que se otorga en los países de origen a quienes integran el contingente anual.

Asimismo, sólo pueden solicitar la prestación de desempleo, "las personas que cumplan los requisitos establecidos en el art. 207" (art. 209.1 LGSS), además de que "la solicitud [de desempleo] requerirá la inscripción como demandante de empleo si la misma no se hubiera efectuado previamente"; lo mismo cabe decir respecto de la necesidad de "acreditar disponibilidad para buscar activamente empleo y para aceptar colocación adecuada" (art. 207.c LGSS). No estando al alcance de los extranjeros en situación irregular la cumplimentación de esos trámites, es claro que tampoco pueden acceder a las prestaciones por desempleo. A mayor abundancia, la OMTAS 22 noviembre 2006, por la que se regula la inscripción de trabajadores extranjeros no comunitarios en los Servicios Públicos de Empleo y en las Agencias de Colocación, sólo acepta la inscripción de "los extranjeros que en aplicación de la vigente normativa sobre permanencia y trabajo de los extranjeros en España, tengan reconocido el derecho de acceso al mercado de trabajo". Y en su artículo 2, al enumerar los "documentos acreditativos que dan derecho de acceso al mercado de trabajo" exige siempre la "autorización de residencia", además de estar "en posesión de una autorización administrativa para trabajar o bien, no estando en posesión de ella, y encontrándose legalmente en España, estar en condiciones de acceder a ella".

Criterios sostenidos.- Carece del derecho a las prestaciones el extranjero, despedido de forma improcedente, que ha desarrollado su actividad laboral de forma irregular (STS 18 marzo 208 (RJ 2008, 2065) (Ponente, Sr. Samper Juan; Pleno)). El TS hace una interpretación restrictiva y nada favorecedora de los intereses de los inmigrantes que estén en situación irregular en España: no tienen derecho a cobrar la prestación por desempleo, aunque hayan trabajado por cuenta ajena. La Ley de Extranjería tiene como fin «incentivar la 
entrada y estancia regular en España» y, a partir de ahí, el TS, desautorizando gran parte de la corriente doctrinal de los Tribunales superiores de las Comunidades Autónomas, favorables a dar la protección al extranjero que está en España en situación irregular, sienta dos principios fundamentales: a) en primer lugar, que el reconocimiento de la protección por desempleo al extranjero en situación irregular en España supondría, entre otras cosas, no sólo ampliar la cobertura a todas las prestaciones de la Seguridad Social, sino también, y como consecuencia de ello, «quitar incentivos al ciudadano que acude a los complejos trámites administrativos para conseguir una autorización de residencia y trabajo»; y, b) en segundo lugar, la concesión de la prestación por desempleo a los extranjeros sin papeles «implicaría la creación judicial de una especie de regularización, encubierta y en espiral, porque, de acuerdo con la Ley de Extranjería, no podrían ser expulsados mientras recibiesen esta prestación».

\section{RESPONSABILIDAD EMPRESARIAL POR PRESTACIONES DE SEGURIDAD SOCIAL}

\subsection{Accidente laboral de persona sin alta}

El problema.- La cuestión litigiosa de plantea con motivo de accidente de trabajo sufrido por un súbdito ecuatoriano, sin permiso de trabajo ni de residencia, que venía prestando servicios para una determinada empresa. El trabajador reclamó jurisdiccionalmente el derecho a recibir asistencia sanitaria y las prestaciones económicas derivadas de accidente de trabajo a cargo de la empresa, sin perjuicio de que la Mutua anticipase las prestaciones, y sin perjuicio también de la responsabilidad del INSS y de la TGSS. Tanto en la instancia como en suplicación su pretensión fue atendida; recurre en casación para unificación de doctrina la TGSS.

Los argumentos.- La Sala Cuarta, rectificando, al calor del nuevo marco normativo representado por la LO 4/2000 de Derechos y Libertades de los extranjeros en España, su anterior doctrina sobre los efectos anulatorios de la carencia de los permisos de residencia y de trabajo sobre el contrato laboral, va a confirmar dichos pronunciamientos, en base a los siguientes y concatenados argumentos:

$1^{\circ}$ ) La doctrina del propio TS sobre la responsabilidad empresarial respecto de accidente de trabajo sufrido por trabajador que no se halla en situación de alta ni, por tanto, ha cotizado por dicha contingencia, sin perjuicio del deber de anticipo de la Mutua y de la responsabilidad subsidiaria de las entidades gestoras -como se sabe, sobre la empresa pesa la obligación de instar la afiliación y/o alta de sus trabajadores (art. 100 LGSS), siendo ello compatible con la llamada "alta de pleno derecho" a través de la cual se inmuniza a los mismos frente a las consecuencias del incumplimiento empresarial en ciertos casos; esto es lo que suele conocerse como regla o principio relativo a la automaticidad de las prestaciones-. Esta doctrina se declara aplicable al supuesto de extranjero no autorizado legalmente para trabajar, toda vez que:

a) El art. 33.3 de la LO 4/2000, de 11 de enero, vigente en la fecha en que se produjo el accidente, establecía que "los empleadores que contraten a un trabajador extranjero deberán solicitar y obtener autorización previa del Ministerio de Trabajo y Asuntos Sociales. La carencia de la correspondiente autorización para contratos por parte del empleador, sin perjuicio de las responsabilidades a que dé lugar, no invalidará el contrato de trabajo respecto a los derechos del trabajador extranjero".

b) El art. 106.1 de la LGSS establece que la obligación de cotizar se inicia con la prestación de servicios por cuenta ajena, precepto determinante de que la Sala de lo 
Contencioso-Administrativo del TS (sentencia de 2 de diciembre de 1998) haya declarado la obligatoriedad de cotizar por los extranjeros que presten servicios sin las correspondientes autorizaciones y permisos. Que el alta en Seguridad Social y la cotización consiguiente devinieran imposibles por falta de las preceptivas licencias de trabajo y residencia constituye un efecto derivado y aceptado por el empresario incumplidor de su obligación básica: contratar únicamente a trabajadores extranjeros en situación regular.

c) El contrato de trabajo del extranjero sin permiso no es, en la actual legislación, un contrato nulo. Y siendo ello así, tampoco puede verse privado de una protección que, en nuestro sistema de relaciones laborales, es inherente al contrato de trabajo y así lo ha sido siempre desde la primitiva Ley de Accidentes de Trabajo de 1900.

$2^{\circ}$ ) No existe precepto alguno que excluya el efecto normal del accidente respecto a trabajadores que no se hallan en alta. El art. 57.d) LOEx impide que la sanción de expulsión se imponga a "los que sean beneficiarios de una prestación por incapacidad permanente para el trabajo como consecuencia de un accidente de trabajo"; a decir de la sentencia, este precepto reconoce "la posibilidad legal de que el extranjero, no debidamente documentado, haya recibido la protección legal en supuesto de accidente de trabajo". La argumentación es aguda, pero discutible por varias razones. Primero, porque invoca la redacción de un precepto conforme a la LOEx 8/2000, cuando los hechos acaecen bajo la vigencia de la versión originaria de la Ley y antes se ha resaltado que procede aplicar el art. 33.3 (crucial para el caso). Segundo, porque la previsión casa bien con la posibilidad de que la prestación derive de accidente de trabajo sufrido por extranjero que presta su actividad sin permiso, pero en modo alguno comporta que ello pueda ser así. Dicho de otro modo: se trataría de un mero argumento confirmatorio y no generador de derechos. En suma, la norma se mueve en un plano diverso al de los derechos contractuales y de Seguridad Social; presuponiendo que existe una pensión de incapacidad, asigna efectos en orden a la permanencia en territorio español, pero sin definir cuándo se devenga aquélla.

$3^{\circ}$ ) El hecho de que Ecuador no haya ratificado el Convenio 19 de la OIT, que subordina la obligación de dispensar el mismo trato a los extranjeros que a los súbditos nacionales a que el país del trabajador lo haya ratificado, no impide la conclusión expuesta, pues en nuestra legislación la Orden de 28 de diciembre de 1966 dispuso que la reciprocidad se entenderá reconocida en todo caso respecto a las contingencias de accidentes de trabajo y enfermedad profesional.

$4^{\circ}$ ) Además, el Convenio Adicional al de la Seguridad Social Hispano Ecuatoriano de 1 de abril de 1960 dispone en su art. 2 que "los trabajadores españoles en Ecuador y los trabajadores ecuatorianos en España estarán sujetos a las legislaciones sobre seguridad social aplicables en los respectivos países y se beneficiarán de las mismas, así como sus familiares y derechohabientes, en iguales condiciones que los nacionales de cada uno de los países". Remisión que supone la aplicación también de las normas sobre automaticidad de las prestaciones en idénticos términos que a los súbditos nacionales".

En suma: el empresario responde directamente de las prestaciones por accidente de trabajo que sufre un trabajador extranjero por él empleado sin la preceptiva autorización para trabajar y no habiéndolo dado de alta en Seguridad Social, sin perjuicio del deber de anticipo de la Mutua y la responsabilidad subsidiaria del INSS y la TGSS (SSTS 9 junio 2003 (RJ 2003, 3936) (Ponente, Sr. Martínez Garrido); 29 septiembre 2003 (RJ 2003, 7446); 7 octubre 2003 (RJ 2003, 6497)).

El criterio sintetizado.- El razonamiento axial de la STS estudiada puede reconducirse fácilmente a la técnica de un silogismo: $1^{\circ}$ ) Del contrato de trabajo deriva protección frente al 
accidente laboral aunque no exista alta en Seguridad Social (Premisa mayor). $2^{\circ}$ ) Los extranjeros que trabajan sin haber obtenido previamente el preceptivo permiso están vinculados con la empresa por un contrato de trabajo (Premisa menor). $3^{\circ}$ ) A los extranjeros que trabajan sin dar de alta, por impedirlo el carácter irregular de su actividad, les es aplicable la protección frente al accidente de trabajo conforme a la construcción sobre automaticidad de las prestaciones (Conclusión).

Reforzando la acertada solución que se acoge, se invocan tres argumentos adicionales, aunque de muy diversa entidad:

\subsection{Accidente laboral con suplantación de personalidad}

El criterio principal.- El empresario responde directamente de las prestaciones por accidente de trabajo que sufre un trabajador extranjero por él empleado sin la preceptiva autorización para trabajar y no habiéndolo dado de alta en Seguridad Social, sin perjuicio del deber de anticipo de la Mutua y la responsabilidad subsidiaria del INSS y la TGSS (SSTS 9 junio 2003 (RJ 2003, 3936)(Ponente, Sr. Martínez Garrido); 29 septiembre 2003 (RJ 2003, 7446); 7 octubre 2003 (RJ 2003, 6497)).

Sin embargo, carece del derecho a las prestaciones el extranjero en situación irregular que ha suplantado la personalidad de otro que sí estaba autorizado para trabajar (STS 21 enero 2010 (RJ 2010, 1264; Sala general) (Ponente, Sr. Moliner Tamborero)).

Supuesto práctico.- Un ciudadano de Guinea Conakry, que carecía de autorizaciones de residencia y trabajo en España y que en 2005 había sido expulsado del territorio nacional con prohibición de entrada, comenzó a trabajar para la empresaria demandada como peón agrícola en la campaña de la aceituna, presentando para formalizar el alta en la Seguridad Social la documentación de otra persona, cuya identidad asumió a estos efectos. La empresa, que desconocía que la identidad fuera falsa, realizó las correspondientes cotizaciones a la Seguridad Social. El demandante sufrió un accidente de tráfico cuando acudía al trabajo, iniciándose el correspondiente procedimiento de declaración de incapacidad permanente. Se trata de saber si el error sobre la persona del trabajador provocado por la suplantación de la identidad de otra persona que sí tenía los correspondientes permisos de trabajo determina la nulidad del contrato de trabajo; nulidad que, a su vez, implica la del encuadramiento en la Seguridad Social y excluye la responsabilidad de la empresa y de la entidad que asumió la cobertura del accidente.

Inexistencia de contrato.- El supuesto examinado ahora no es el del empresario incumplidor a sabiendas, sino que la nulidad surge por la actuación dolosa del trabajador. En cierta forma, el enfoque del problema entronca con el abordado al sentar el criterio conforme al cual carece del derecho a las prestaciones el extranjero, despedido de forma improcedente, que ha desarrollado su actividad laboral de forma irregular (STS 18 marzo 208 (RJ 2008, 2065) (Ponente, Sr. Samper Juan; Sala general)).

En el supuesto descrito no hubo contrato por cuanto faltó uno de los requisitos esenciales del mismo conforme a lo dispuesto en el art. $1261 \mathrm{CC}$; el error sustancial reseñado invalida el consentimiento conforme al art. $1266 \mathrm{CC}$. A partir de la inexistencia y consiguiente nulidad el contrato celebrado en el presente caso entre el trabajador extranjero y su empresaria, los únicos efectos del mismo serán los que deriven de la aplicación del art. 9 ET, los que reconoce a todo trabajador extranjero el art. 14.3 de la propia LOEX, o los que puedan derivar de responsabilidad extracontractual; no pudiendo afirmarse que la normativa de Seguridad Social permita extender su protección a quienes se hallasen en la situación de ilegalidad del demandante. 
Inaplicabilidad de las normas protectoras.- El régimen de protección social establecido para la cobertura de los daños derivados de un accidente laboral deviene inaplicable pues presupone la existencia de un previo contrato de trabajo del que resulte responsable un empleador. Ello es así pese a la automaticidad y anticipo de prestaciones porque siempre, al final el responsable último por subrogación es el empresario cuando resulta ser el incumplidor de sus obligaciones previas.

El art. 36.3 LOEx rige solo para los supuestos en los que aquella autorización que habilita al trabajador para residir en nuestro país por el tiempo de trabajo no la ha solicitado y obtenido el empresario antes de contratar a un trabajador. Cuando el empleador no pudo pedir esa autorización para el trabajador accidentado sino que la pidió para otro debido a la propia actuación dolosa del propio trabajador, "no podrá afirmarse que la carencia de la autorización era imputable al empleador, y por ello no podrá sostenerse tampoco por esta vía ninguna responsabilidad a él imputable".

Es sobre la "irregularidad" del empresario sobre la que la LOEx dispone que no se considera inválido el contrato e imputa al empresario las responsabilidades que de la misma se deriven como claramente se aprecia en el inicio de su redacción cuando toda esa responsabilidad la hace derivar de "la carencia de la correspondiente autorización por parte del empresario". El legislador ha relativizado los efectos de lo que sería una nulidad absoluta por infracción de una norma imperativa tan contundente como la de que cualquier trabajador extranjero "precisará" aquellas autorizaciones para trabajar en España en aplicación de las previsiones de excepción del art. 6.3 "in fine" del Código Civil, sobre la base de aquella irregularidad empresarial, entendiendo con defendible criterio de justicia que en los supuestos en que la irregularidad era del empresario habría de ser éste y no el trabajador el responsable de los daños de todo tipo derivados de aquella irregularidad. Cuando la carencia de aquellas autorizaciones no es debida a un incumplimiento "por parte del empleador" sino a una actuación dolosa del trabajador como en el caso ha ocurrido, desaparece el condicionante relativizador del apartado 3 del art. 36 CC para quedar incumplida una norma prohibitiva en toda su puridad y con todas sus consecuencias cual es la nulidad de pleno derecho del contrato celebrado.

El Voto Particular del Sr. Desdentado Bonete.- Resumiendo al máximo este extenso Voto Particular: $1^{\circ}$ ) la simulación de la identidad ha determinado no sólo la nulidad del contrato de trabajo, sino la nulidad del alta del actor en la Seguridad Social; $2^{\circ}$ ) no estaba ni podía estar legalmente en alta y, por tanto, no podía causar derecho a las prestaciones de la Seguridad Social por accidente de trabajo, $3^{\circ}$ ) no puede aplicarse la asimilación al alta del artículo 42.2 del Real Decreto 84/1996, porque es contraria a la Ley; $4^{\circ}$ ) no existe tampoco responsabilidad indemnizatoria del empresario, porque la simulación de la identidad determina que no le sea imputable a éste ni el encuadramiento irregular del actor en la Seguridad Social, ni el incumplimiento de las normas sobre empleo de extranjeros.

Hay que aclarar que sería, sin embargo, posible la cobertura de los daños provocados por el accidente de trabajo cuando en los mismos concurriese responsabilidad por culpa del empresario como consecuencia del incumplimiento de normas de prevención.

El Voto Particular de la Sra. Segoviano Astaburuaga.- La nulidad del contrato de trabajo por ocultamiento de los datos reales de su personalidad por parte del trabajador extranjero, -sin perjuicio de sus responsabilidades penales u de otro orden, en su caso --, no puede llevar a la conclusión de que desaparezca el principio de automaticidad de prestaciones en el supuesto de accidentes de trabajo, regla básica de nuestra legislación protectora, que solo podría obviarse si el trabajador accidentado fuera el único responsable del accidente o lo 
hubiere causado con la finalidad de generar las derivadas prestaciones; pero, entiendo, que no puede inaplicarse tal regla básica en el supuesto analizado, sin perjuicio de la posible exoneración o disminución de la responsabilidad empresarial en el estricto ámbito de la seguridad social.

Valórese que acontecería si la nulidad del contrato de trabajo derivara del hecho de que un menor de dieciséis años, de nacionalidad española, aportara para ser contratado un DNI de una persona mayor de dicha edad y en esas condiciones de ocultación de personalidad fuera contratado laboralmente, de sufrir este trabajador realmente menor de edad laboral un accidente, por estar trabajando en condiciones vulneradoras de las normas básicas de prevención de riesgos laborales, ¿se le privaría también de la protección de la Seguridad Social pública?.

\section{ASISTENCIA SANITARIA EN EL EXTRANJERO}

En coherencia con la preceptiva racionalización de los recursos disponibles, la asistencia sanitaria a cargo de la Seguridad Social ha de recibirse de las instituciones o profesionales por ella misma designados, sin que el beneficiario posea total libertad para elegir qué desea. En el plano económico, ello conduce a que los eventuales gastos por tal causa que se hayan generado fuera del sistema sanitario habilitado por la Seguridad Social hayan de ser afrontados por el propio enfermo, salvo en supuestos excepcionales -conforme al art. 102.3 LGSS de 1974 "las Entidades obligadas a prestar la asistencia sanitaria no abonarán los gastos que puedan ocasionarse cuando el beneficiario utilice servicios médicos distintos de los que hayan sido asignados, a no ser en los casos que reglamentariamente se determinen-.

Pero, precisamente, uno de los aspectos más litigiosos respecto de la prestación de asistencia sanitaria en el marco del sistema de Seguridad Social se refiere al alcance de la excepción mencionada; conforme a ella, hay supuestos en que pese a haberse recabado de instituciones ajenas a aquél, la Entidad Gestora viene obligada al reintegro de los gastos afrontados, bien por causa de urgencia vital, bien por negativa injustificada a su prestación. Un ramillete de criterios sentados a propósito de este tipo de asuntos es el siguiente:

- Es inexistente el derecho al reintegro de gastos ocasionados por asistencia prestada en el extranjero para enfermedad no tratada por la Seguridad Social española (SSTS 13 octubre 1994 (RJ 1994, 8050) (Ponente, Sr. Fernández López); 30 noviembre 1994 (RJ 1994, 9724); 8 febrero 1995 (RJ 1995, 788); 21 diciembre 1995 (RJ 1996, rec. 1967/95); 8 marzo 1996 (RJ 1996, rec. 2637). Doctrina colateral o complementaria de la principal reseñada es que la absolución del INSALUD o Entidad análoga comporta la de la TGSS, pues que en cuanto servicio común no asume responsabilidad directa respecto de las prestaciones dinerarias, sino que satisface las que tengan por titular a la Entidad Gestora correspondiente).

- Tampoco cuando el demandante se trasladó por iniciativa propia y sin autorización de la Seguridad Social española a un centro extranjero, aduciendo que la ausencia de prescripción de tratamiento inmediato tras la intervención quirúrgica a que fue sometido constituye un supuesto de denegación injustificada de asistencia (STS 26 abril 1996 (RJ 1996, 3616) (Ponente, Sr. Fernández López)), o bien eludiendo de tal modo la lista de espera en orden a la práctica de un trasplante renal (STS 7 octubre 1996 (RJ 1996, rec. 109/1996) (Ponente, Sr. Martínez Emperador)).

- En supuestos de urgencia vital, procede el reintegro de gastos ocasionados por la asistencia sanitaria prestada en país extranjero, aunque no exista convenio de asistencia 
sanitaria con aquel país (STS 4 abril 2000 (RJ 2000, rec. 3104/99) (Ponente, Sr. Salinas Molina)).

- Procede el reintegro de gastos por la asistencia sanitaria proporcionada en el extranjero, si se ha presentado inesperadamente una situación de urgencia vital con motivo de un viaje realizado fuera de nuestras fronteras y que no había sido proyectado con tal fin (STS 21 marzo 2002 (RJ 2002, 9884) (Ponente, Sra. Calvo Ibarlucea)).

- Procede el reintegro de la totalidad de los gastos generados por una intervención sanitaria de urgencia realizada en otro país comunitario, incluidos los gastos de los que no se hace cargo el Estado en el que se ha prestado la asistencia conforme a su propia legislación (SSTS de 4 marzo 2010 (RJ 2010, 2477) (Ponente, Sr. Agustí Juliá) y 13 julio 2010 (RJ 2010, 6815). En su sentencia de 16 de mayo de 2006 (TJCE 2006, 141) Asunto C-372/2004 (Watts), el Pleno del TJCE ha dictaminado que "El artículo 49 CE debe interpretarse en el sentido de que, en el supuesto de que la legislación del Estado miembro competente establezca la gratuidad de la asistencia hospitalaria dispensada en el marco de un servicio nacional de salud, y de que la legislación del Estado miembro en el que un paciente afiliado a dicho servicio ha sido autorizado, o hubiera debido ser autorizado, a recibir tratamiento hospitalario a cargo de dicho servicio no prevea una cobertura íntegra del coste de dicho tratamiento, la institución competente debe conceder a dicho paciente un reembolso equivalente a la eventual diferencia entre, por una parte, el coste objetivamente cuantificado de un tratamiento equivalente en un establecimiento integrado en el servicio de que se trate, con un límite máximo, en su caso, correspondiente al importe global facturado por el tratamiento dispensado en el Estado miembro de estancia, y, por otra parte, el importe que la institución de este último Estado miembro esté obligada a cubrir por cuenta de la institución competente, en virtud del artículo 22, apartado 1, letra c), inciso i), del Reglamento núm. 1408/71, con arreglo a las disposiciones de la legislación de dicho Estado miembro").

\section{7. ÁMBITO DE LA JURISDICCIÓN ESPAÑOLA}

\subsection{Trabajadores extranjeros de embajadas españolas}

Problema.- Se suscita de nuevo el problema consistente en determinar si la jurisdicción española es competente para conocer de la pretensión esgrimida por un extranjero que es contratado en su país para prestar servicios en la Embajada del Estado español en dicho país.

Ley aplicable al contrato y jurisdicción competente.- Acertadamente, el Tribunal Supremo comienza por deslindar dos problemas diversos: la determinación del ordenamiento sustantivo o material que haya de gobernar el negocio jurídico y el señalamiento de la jurisdicción competente para resolver eventuales conflictos.

El art. $6^{\circ}$ del Convenio de Roma de 19 de junio de 1980 (BOE 19 julio 1993), en línea con lo preceptuado en el art. 10.6 del Código Civil español, indica cuál debe de ser la "ley aplicable" al contrato de trabajo: la pactada o, en su defecto, la del lugar donde habitualmente se desarrolle la actividad laboral. Tal y como su propia denominación indica, se está ante norma aplicable a las obligaciones contractuales en la que lo hecho es determinar la legislación que ha de regular una relación jurídica en la que exista algún elemento de extranjería. Esa idea se confirma por el propio Convenio puesto que su art. 1.2.h) advierte que el mismo no se aplica "al proceso" y el art. 10, al especificar el ámbito de la ley del contrato, omite la determinación de la jurisdicción competente. Si acaso, podría dudarse qué significa el art. 10.2, conforme al cual "en lo que se refiere a las modalidades del 
cumplimiento y a las medidas que debe tomar el acreedor en caso de cumplimiento defectuoso, se tendrá en cuenta la Ley del país donde tenga lugar el cumplimiento", pero el contexto de la norma y las previsiones ya referidas conducen a descartar la virtualidad jurisdiccional de tal previsión.

Buscando la norma que determine la eventual competencia de la jurisdicción española se desemboca en el art. 25 de la LOPJ, en el que se atribuye jurisdicción a los órganos españoles atendiendo a varios criterios:

$1^{\circ}$ ) Criterio personal: En materia de derechos y obligaciones derivados de contrato de trabajo, los Juzgados y Tribunales españoles serán competentes cuando el trabajador y el empresario tengan nacionalidad española, cualquiera que sea el lugar de prestación de los servicios, o de celebración del contrato;

$2^{\circ}$ ) Criterio territorial: En materia de derechos y obligaciones derivados de contrato de trabajo, los Juzgados y Tribunales españoles serán competentes cuando los servicios se hayan prestado en España o el contrato se haya celebrado en territorio español;

$3^{\circ}$ ) Criterio representativo: En materia de derechos y obligaciones derivados de contrato de trabajo, los Juzgados y Tribunales españoles serán competentes cuando el demandado tenga su domicilio en territorio español o una agencia, sucursal, delegación o cualquier otra representación en España;

$4^{\circ}$ ) Criterio especial: En materia de derechos y obligaciones derivados de contrato de trabajo, los Juzgados y Tribunales españoles serán competentes en el caso de contrato de embarque, si el contrato fue precedido de oferta recibida en España por trabajador español.

De este modo, el art. 25 de la LOPJ traza un cuadro de conexiones competenciales con el denominador común del principio de territorialidad, sea por referencia al lugar en que se trabaja o en que tiene su sede la empresa, con la apertura a los supuestos en que ambas partes posean nacionalidad española.

Criterio.- Descartado que se esté ante supuesto en que la soberanía nacional entre en juego y opere algún tipo de inmunidad diplomática, hay que trasladar las previsiones de la LOPJ al asunto de referencia. El art. 21.1 LOPJ establece que "los Juzgados y Tribunales españoles conocerán de los juicios que se susciten en territorio español entre españoles, entre extranjeros y entre españoles y extranjeros con arreglo a lo establecido en la presente Ley y en los tratados y convenios internacionales en los que España sea parte". Luego, no existiendo previsión contraria en los Convenios o Tratados Internacionales, ha de estarse a los términos en que el art. 25 de la misma LOPJ admite la competencia de los Tribunales españoles.

En suma, competen a la jurisdicción española los pleitos laborales respecto de los trabajadores extranjeros contratados en su país para prestar servicios en embajadas españolas (SSTS 29 septiembre 1998 (RJ 1998, rec. 4796/1997) (Ponente, Sr. Sampedro Corral; 20 noviembre 1998 (RJ 1998, rec. 940/98)). De este modo, siendo demandada la Administración española, deriva con naturalidad la competencia de los órganos nacionales, en concordancia con la general validez que en el orden civil de la jurisdicción tiene el domicilio del demandado a efectos de determinar la competencia jurisdiccional (art. 22.2 ${ }^{\circ}$ LOPJ).

\subsection{Despido del tripulante de Ryanair}

Cuestión a dirimir.- El asunto que se somete a la consideración de la Sala Cuarta del TS consiste en determinar si los tribunales españoles son o no competentes para conocer de una demanda de despido de un trabajador domiciliado en España, cuando: a) ninguna de las codemandadas como empleadoras tiene domicilio social en España sino en otro país comunitario; b) una de las empleadoras tiene oficina en España; c) el contrato de trabajo no 
se suscribió en España; d) la prestación de servicios se efectúa fuera de España; y, e) finamente, aun existiendo una cláusula de sumisión a unos tribunales en un país comunitario, la misma se pactó en el propio contrato de trabajo.

El proceso de instancia se inició por demanda en reclamación por despido disciplinario nulo o subsidiariamente improcedente, contra las sociedades "Workforce International Contractors Limited" (WFI) y contra "Ryanair Limited". El actor prestaba servicios para WFI, con la categoría de auxiliar de cabina, iniciándose su relación en fecha 14-07-2007. En la fecha del despido, entre el actor y la compañía estaba vigente un contrato para prestar servicios en las aeronaves de Ryanair con base en el Aeropuerto de Oslo y con una cláusula 35 "de sumisión a los tribunales irlandeses". Consta igualmente acreditado, que: a) el demandante tiene su domicilio en Madrid, a donde acudía solo los días de libranza, permaneciendo los días laborables en Oslo, siendo titular de un permiso de Residencia en Noruega; b) la empresa WFI, con licencia para operar como Agencia de Empleo, tiene el domicilio en Irlanda, careciendo de oficinas en España; y c) la empresa Ryanair tiene su domicilio en Dublín, pero en los hechos probados de la sentencia de instancia consta que tiene una oficina abierta en el Aeropuerto de Madrid-Barajas, donde fueron emplazadas las dos empresas demandadas.

Normativa aplicable al caso.- Tras efectuar un profuso recorrido por las sentencias en las que previamente la Sala Cuarta se ha pronunciado sobre la competencia de los tribunales españoles para conocer de reclamaciones derivadas del contrato de trabajo, el Tribunal Supremo recuerda que las reglas de competencia internacional vienen configuradas por un sistemas de normas que se estructuran en torno a un principio de jerarquía y prioridad, de tal suerte que debe procurarse, en primer término, la aplicación de la normativa internacional y/o de la Unión Europea sobre competencia judicial, y sólo en caso de no ser esto posible, acudir al Derecho autónomo (interno) que aparece configurado por el art. 25 LOPJ.

La normativa internacional en la materia competencial que aquí se considera estaba conformada inicialmente por el Convenio de Bruselas de 27 septiembre 1968, relativo a la competencia internacional y a la ejecución de resoluciones judiciales en materia civil y mercantil, y por el Convenio de Lugano de 16 septiembre 1988, con el mismo objeto que el de Bruselas e incluyendo igualmente a los países integrantes de la Asociación Europea de Libre Comercio -AELC, entre los que se encuentra Noruega. El Convenio de Bruselas dio paso al Reglamento CE 44/2001, Reglamento del Consejo de 22 diciembre 2000 (llamado "Bruselas I") en vigor desde el 01-03-2002; debiendo destacarse, como pone de relieve la STJUE 22 mayo 2008 (C-462/06), que las reglas de competencia en materia de contratos individuales de trabajo que establece el Reglamento difieren considerablemente de las reglas aplicables en ese ámbito en virtud del Convenio de Bruselas. Este Reglamento ha sido derogado por el Reglamento (UE) n ${ }^{\circ}$ 1215/2012, de 12 diciembre 2012 (LCEur 2012, 2110), que aplicable a partir del 10 enero 2015, con excepción de los arts. 75 y 76 (referidos a obligaciones de los Estados miembros) que serán aplicables a partir del 10 enero 2014 (art. 81).

En asunto que aquí se trata, la norma principal aplicable para la determinación de la competencia internacional de los tribunales españoles está constituida por el Reglamento CE 44/2001, coincidente en esta materia con la contenida en el ulterior Reglamento UE $1215 / 2012$, aunque no aplicable al caso por razones temporales. Este Reglamento prevalece sobre el citado art. $25.1^{\circ}$ LOPJ, puesto que, conforme al citado Reglamento (CE) $n^{\circ} 44 / 2001$ del Consejo, las personas domiciliadas en un Estado miembro sólo podrán ser demandadas ante los tribunales de otro Estado miembro y no podrán invocarse frente a ellas, en particular, 
las reglas de competencia nacionales (art. 3) y únicamente si el demandado no estuviere domiciliado en un Estado miembro, la competencia judicial se regirá, en cada Estado miembro, por la ley de este Estado miembro (art. 4.1), no aconteciendo esto último en el presente caso.

Doctrina de la Sala Cuarta.- Los tribunales españoles no son competentes para conocer del despido de un trabajador domiciliado en el País, cuando ninguna de las codemandadas como empleadoras tiene domicilio social en él sino en otro comunitario, si bien una de ellas cuenta con oficina en Madrid; el contrato de trabajo no se suscribió en España, la prestación de servicios se efectúa fuera de España y, finalmente, aun existiendo una cláusula de sumisión a unos tribunales de un país comunitario, la misma se pactó en el propio contrato de trabajo (STS de 30 diciembre 2013 (RJ 2013, 8369)(Ponente, Sr. Salinas Molina)).

Entiende la Sala Cuarta que el lugar en que tengan los demandados su domicilio es el determinante para fijar la competencia internacional en la presente litis, pues, tratándose de empresarios domiciliados en un Estado miembro, serán competentes los tribunales del Estado donde el empresario demandado tenga el domicilio, o a elección del propio trabajador demandante, los tribunales del Estado donde desempeñare habitualmente su trabajo o ante el tribunal del último lugar en que lo hubiere desempeñado, o si el trabajador no desempeñare o no hubiere desempeñado habitualmente su trabajo en un único Estado, ante el tribunal del lugar en que estuviere o hubiere estado situado el establecimiento que hubiere empleado al trabajador, todo ello a salvo de que concurrieran competencias exclusivas (que no son de aplicación a la materia laboral) ( arts. 18.1 y 19 Reglamento CE 44/2001), o que las partes hubieran comprometido expresamente su sumisión expresa a los tribunales de un determinado Estado mediante un pacto celebrado después del nacimiento del litigio o, cuando se celebre con anterioridad, permita al trabajador formular demandas ante tribunales distintos de aquellos a los que las reglas del citado Reglamento confieren la competencia ( art. 21 Reglamento CE 44/200, en su interpretación jurisprudencial) -el mayor interés de esta compleja y extensa sentencia radica en el pormenorizado análisis que realiza de los diversos fueros contemplados en el Reglamento CE 44/2001 (hoy en día sustituido por el Reglamento UE 1215/2012)-.

En aplicación de los arts. 18 y 19 del Reglamento CE 44/2001 (que prevalece sobre el art. $25.1^{\circ}$ LOPJ), se llega a la conclusión de que no corresponde a los tribunales sociales españoles enjuiciar un litigio derivado de un contrato de trabajo individual (en el caso, por despido) si, como en el caso, las demandadas como empleadoras tienen su domicilio social en otro país comunitario (en el caso, Irlanda) y la prestación de servicios se hizo fuera de España (en el caso, en Noruega), siendo irrelevante que el trabajador sea español, con domicilio en España y una de ellas tuviera oficina (que no domicilio social) en España.

\subsection{Reclamación de prestaciones de Seguridad Social por extranjeros}

Normas aplicables.- El artículo 21 LPOJ atribuye al conocimiento de los Juzgados y Tribunales españoles los juicios que se susciten en territorio español entre españoles, entre extranjeros y entre españoles y extranjeros con arreglo a lo establecido en la propia Ley y en los tratados y convenios internacionales en los que España es parte, como ocurre en el presente supuesto, en que resultan demandados entes españoles y domiciliados en España.

El artículo 25.3 de la Ley Orgánica del Poder Judicial es concluyente al atribuir a los Juzgados y Tribunales españoles competencia «en materia de prestaciones de la Seguridad Social frente a entidades españolas o que tengan domicilio, agencia o delegación o cualquier otra representación en España». La regla transcrita es clara y precisa en cuanto al ámbito en 
que atribuye competencia a los Tribunales españoles cuando se ejercitan acciones frente a entidades españolas de Seguridad Social, como en el caso presente sucede.

En lo que respecta a las empresas demandadas, no es aplicable lo dispuesto en el artículo 25.3 LOPJ, pues no se trata de pretensiones ejercitadas en materia de Seguridad Social, frente a entidades españolas o que tengan domicilio, agencia, delegación o cualquier otra representación en España. Respecto de ellas, conforme al art. 25.1 LOPJ, los tribunales españoles carecen de competencia dado que no se encuentran en ninguno de los supuestos en los que la regla atribuye competencia a los tribunales españoles, al no haber sido contratado el trabajador ni prestado servicios en España, y no tienen esas demandadas, al menos no hay constancia de ello, domicilio, agencia, sucursal, delegación o cualquier otra representación en España, ni tienen nacionalidad española. En estas condiciones, su presencia en este litigio no obedece a razones de litisconsorcio pasivo necesario, puesto que no se harán pronunciamientos contra ellas, y no tendría otra finalidad que la simple de tomar conocimiento de lo debatido en este litigio.

Criterio de la Sala Cuarta.- Los tribunales españoles son competentes para conocer de una demanda en la que un ciudadano marroquí que trabajó en España hasta finales de los años setenta solicita el reconocimiento de una pensión de incapacidad permanente absoluta con cargo a la Seguridad Social Española; la falta de antecedentes administrativos sobre el demandante no conlleva un pronunciamiento de incompetencia de los tribunales españoles, sino, en su caso, la desestimación de la pretensión (STS 2 marzo 2000 (RJ 2000, 2591) (Ponente, Sr. Gil Suárez)).

También para conocer sobre pretensión ejercida por español frente al INSS y otros entes españoles, pese a que sólo trabajó para empresa extranjera en Venezuela y se había pactado la sumisión a los tribunales suizos; hay incompetencia por lo que se refiere a la empresa extranjera (STS 28 diciembre 2005 (RJ 2006, 1552) (Ponente, Sr. Iglesias Cabero)).

\section{Breve currículo:}

\section{Antonio V. Sempere Navarro}

Catedrático de Derecho del Trabajo y de la Seguridad Social, con vinculación a las Universidades de Oviedo (1986-1987), Murcia (1987-1999) y Rey Juan Carlos (desde 1999); Profesor Extraordinario de la Universidad de Navarra (desde 1987) y de otras iberoamericanas. Consejero Académico de GómezAcebo\&Pombo; Director general de los "Foros Aranzadi Social" (implantados en 23 ciudades); conferenciante invitado en numerosas sedes académicas y profesionales. Autor o Coautor de numerosas monografías jurídicas (en torno a ochenta) y de más de doscientos artículos científicos, además de numerosas colaboraciones menores. Magistrado del Tribunal Supremo desde abril del 2014. 